\title{
A Compact and Low Resolution Spectrometer for the Inversion of Water Vapor Total Column Amounts
}

\author{
E. Sepúlveda ${ }^{\mathrm{a}, \mathrm{b}}$, M. Schneider ${ }^{\mathrm{b}, \mathrm{c}}$, F. Hase ${ }^{\mathrm{c}}$, O. E. García ${ }^{\mathrm{b}}$, M. Gisi ${ }^{\mathrm{c}}$, T. Blumenstock ${ }^{\mathrm{c}}$, \\ S. Dohe ${ }^{\mathrm{c}}$, Y. González ${ }^{\mathrm{b}, \mathrm{c}}$ and J. C. Guerra ${ }^{\mathrm{a}}$ \\ ${ }^{a}$ La Laguna University, Physics Department, Tenerife, Spain \\ ${ }^{b}$ Izaña Atmospheric Research Center, Agencia Estatal de Meteorología (AEMET), Izaña, Spain \\ ${ }^{c}$ Institute for Meteorology and Climate Research (IMK-ASF), Karlsruhe Institute of Technology, Karlsruhe, Germany \\ Correspondence to: esepulvedah@aemet.es
}

\begin{abstract}
Observations of atmospheric water vapor $\left(\mathrm{H}_{2} \mathrm{O}\right)$ amounts are required for the investigation of important and current atmospheric studies, such as the hydrological cycle, energy balance, climate change, etc. In this context, we present a portable, very compact, commercial and very low resolution Fourier transform spectrometer for the remote sensing of total column amounts of $\mathrm{H}_{2} \mathrm{O}$ at a high measurement frequency (one measurement about every 2 minutes). The methodology applied to carry out this work is explained. Moreover, first results are compared with high quality $\mathrm{H}_{2} \mathrm{O}$ total column amounts obtained by a collocated non-mobile high resolution Fourier transform spectrometer. This inter-comparison documents that the very low resolution instrument is well suited for capturing the variability of $\mathrm{H}_{2} \mathrm{O}$ total column amounts (with precision better than $4 \%$ ), but that suffers from a significant wet bias (about 30\%).
\end{abstract}

Keywords: Water vapor, Inversion, Compact Fourier transform spectrometer.

PACS: $92.60 . \mathrm{Jq}$

\section{INTRODUCTION}

Water vapor $\left(\mathrm{H}_{2} \mathrm{O}\right)$ is the main atmospheric gas responsible for regulating weather and climate, and contributes to about $90 \%$ of the Earth's natural greenhouse effect. The continuous cycle of evaporation, vapor transport, cloud formation, and precipitation distributes water and energy around the globe. A continuous monitoring of $\mathrm{H}_{2} \mathrm{O}$ at global scales is important to assess, predict and mitigate future climate change. Currently, different instrumentation (e.g., radiosondes, GPSs, radars, satellites, sunphotometers, and high resolution spectrometers) and different networks (e.g., GCOS, AERONET, and NDACC) are dedicated to this purpose. In this context, we present a portable, very compact, commercial and very low resolution Fourier transform spectrometer for near infrared spectroscopy (ARCspectro ANIR; named throughout the document as $\mu$-FTIR) and suitable for retrieving total column amount of $\mathrm{H}_{2} \mathrm{O}$.

The $\mu$-FTIR has been adapted to measure the solar absorption spectra $(3800-11100 \mathrm{~cm}-1 ; 0.9-2.6 \mu \mathrm{m})$. The very compact $(14.6 \times 10.5 \times 7 \mathrm{~cm})$ spectrometer is based on the lamellar grating concept [1]. One beamsplitter is mounted in the light path and a low power laser is used to control the position of the scanning system (further information can be found at http://www.ftir-spectrometer.com). The $\mu$-FTIR is coupled by means of an optical fiber to a precise solar tracker and through a USB-connector to a PC. The measurements are recorded by commercial software provided by the spectrometer's manufacturer. The instrumental line shape (ILS) of the $\mu$-FTIR was characterized using the code LINEFIT [2] and introduced in the retrieval process. It was estimated that the $\mu$-FTIR achieves a maximum optical path difference of $0.05 \mathrm{~cm}$ (i.e. spectral resolution of $\sim 18 \mathrm{~cm}-1$ ).

A high spectral resolution spectrometer (Bruker IFS 125HR) records the spectra in the same spectral region as the $\mu$ FTIR but at a much higher resolution $(0.02 \mathrm{~cm}-1)$. Recording of one scan takes about 5 seconds for the $\mu$-FTIR and about 25 seconds for the IFS 125HR. In order to increase the signal to noise ratio several scans are co-added ( 6 for the highand 25 for the low- resolution spectrometer) leading to a measurement time for one spectrum of about 2 and 3 minutes for the $\mu$-FTIR and the IFS 125HR, respectively.

The inversion of the $\mathrm{H}_{2} \mathrm{O}$ total column amounts is addressed by the retrieval code PROFFIT [3] either for the lowand high- resolution spectra. This line-by-line algorithm retrieves the concentration of an atmospheric constituent by analyzing the width and intensity of the absorption lines from the measured spectra. However, the very low resolution spectra do not distinguish the individual absorption lines, rather they show the absorption bands. Nonetheless, PROFFIT successfully retrieves $\mathrm{H}_{2} \mathrm{O}$ total amounts from the low- and high- resolution instruments' spectra. 


\section{METHODOLOGY}

This study has been carried out at the Izaña subtropical high mountain observatory (http://www.izana.org/) located at 2370 m.a.s.l. in the Canary Islands. The observatory is located over a strong temperature inversion layer that works as a natural barrier for local pollution and therefore is appropriately representative of atmospheric background conditions. It is a global station of the WMO (World Meteorological Organisation) network of GAW (Global Atmospheric Watch) stations and has a comprehensive measurement program of a large variety of different atmospheric constituents. The IFS 125HR located at the Izaña observatory contributes to the NDACC (Network for the Detection of Atmospheric Composition Change) and TCCON (Total Carbon Column Observing Network) since 1999 and 2007, respectively.

The $\mu$-FTIR and the IFS 125HR are operated side-by-side at the Izaña observatory since June 2011. Both instruments were located a few meters apart and, although two different precise solar trackers were used, both instruments detect almost the same air masses. Under clear sky conditions coincident measurements on 58 different days have been achieved.

The measured spectra have been processed with the nonlinear least squares fitting algorithm PROFFIT. Two different retrieval strategies are followed. For the high resolution spectra 8 microwindows and 3 interfering species $\left(\mathrm{CH}_{4}, \mathrm{CO}_{2}\right.$ and $\mathrm{N}_{2} \mathrm{O}$ ) are considered. An optimal estimation method is applied for the target species [4]. While for the very low resolution spectra we consider a broad absorption band (7990.00-9153.83 cm-1) and simultaneously fit the $\mathrm{H}_{2} \mathrm{O}$ and 2 interfering species $\left(\mathrm{CH}_{4}\right.$ and $\left.\mathrm{CO}_{2}\right)$ according to an a-priori profile.

\section{RESULTS: $\mathrm{H}_{2} \mathrm{O}$ TOTAL COLUMN AMOUNTS}

The atmospheric $\mathrm{H}_{2} \mathrm{O}$ concentrations are very variable in space and time and the rapid integration time of the instruments is very important (with the $\mu$-FTIR we can register a $\mathrm{H}_{2} \mathrm{O}$ total column amount value about every two minutes). The lower panel of Figure 1 shows the $\mathrm{H}_{2} \mathrm{O}$ total column amounts time series obtained for the $\mu$-FTIR (red stars) and the IFS 125HR (black circles). Here, we only consider measurements for which $\mu$-FTIR and IFS $125 \mathrm{HR}$ coincide within 10 minutes (in total 1415 measurements). The typical annual variation can be seen: low values during winter and higher values during summer. The upper panel depicts the relative differences. It shows a large systematic bias of $31 \%$. However, the low standard deviation (3.8\%) suggests a good repeatability of the $\mu$-FTIR measurements.

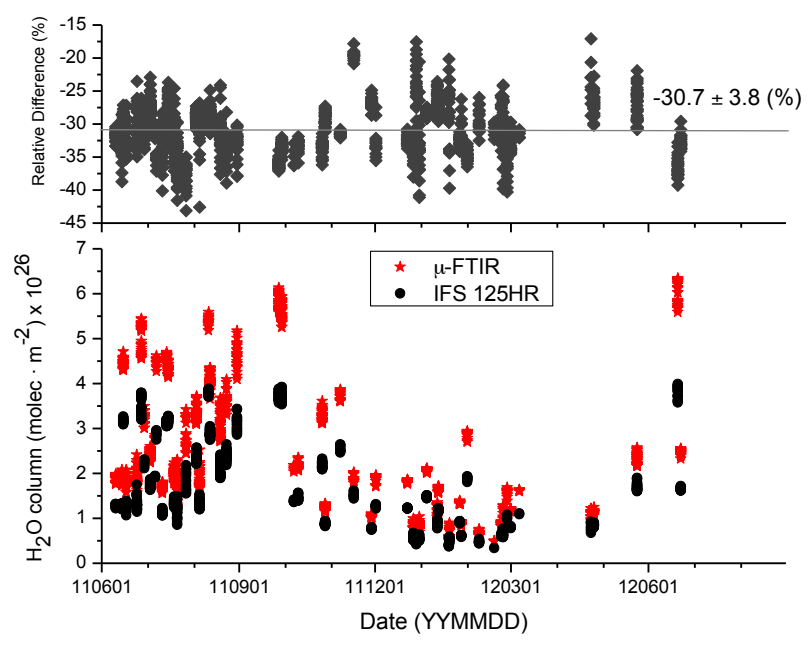

FIGURE 1. Lower panel: Time series of the $\mathrm{H}_{2} \mathrm{O}$ total column amounts for both low- and high- resolution instruments. We only consider measurements that coincide within 10 minutes. Upper panel: time series of the relative difference. The solid line represents the mean relative difference value.

Figure 2 shows the correlation plot between $\mathrm{H}_{2} \mathrm{O}$ total column amounts obtained from the low- and high- resolution instruments (for temporal coincidence criterion of less than 10 minutes). A high correlation factor $(\mathrm{R}=0.99)$ is achieved. However, the $\mu$-FTIR significantly overestimates the IFS 125HR H2O total column amounts (scaling factor IFS125HR / $\mu$-FTIR of 0.7 ). 


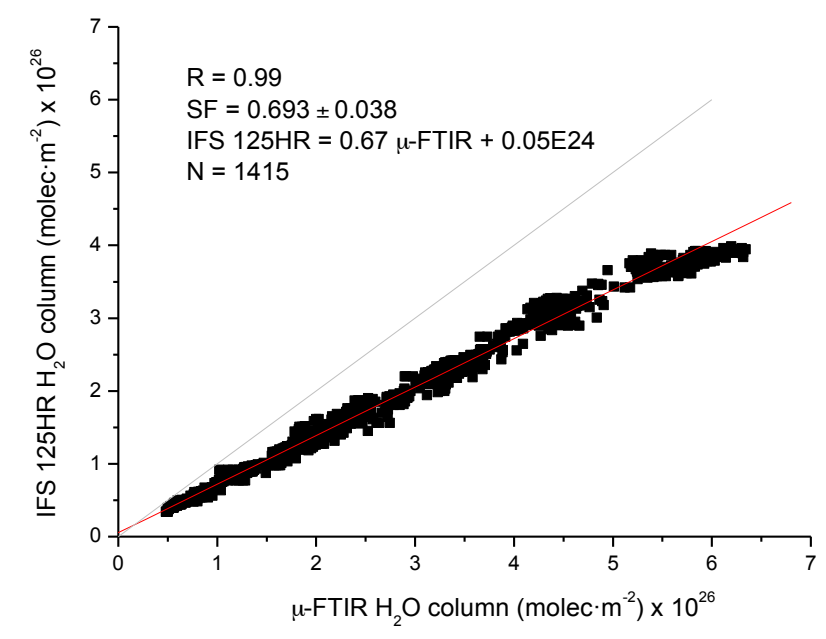

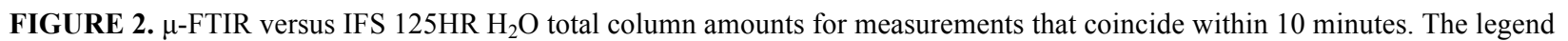
shows some statistic values (R: correlation factor; SF: scaling factor; least square fit, and N: number of data). The red line corresponds to the linear regression line, while the grey line shows the diagonal as a reference.

Figure 3 shows an example of variation of $\mathrm{H}_{2} \mathrm{O}$ total column amounts during 2 hour for the $\mu$-FTIR (red stars) and the IFS $125 \mathrm{HR}$ (black circles). Again, we only consider measurements for which $\mu$-FTIR and IFS $125 \mathrm{HR}$ coincide within 10 minutes. The $\mu$-FTIR data have been scaled applying the scaling factor obtained and showed in Figure 2 (SF $=0.693$ ). The variability of the $\mathrm{H}_{2} \mathrm{O}$ total column amounts is clearly seen and equally registered with both instruments. For this day we get a correlation factor of 0.98 and scaling factor of $0.709 \pm 0.009$ (graphic not shown). Considering daily variation, we get that more than $66 \%$ of the days in our data set show correlation factor $>0.8$ and $89 \%$ standard deviation $<3 \%$.

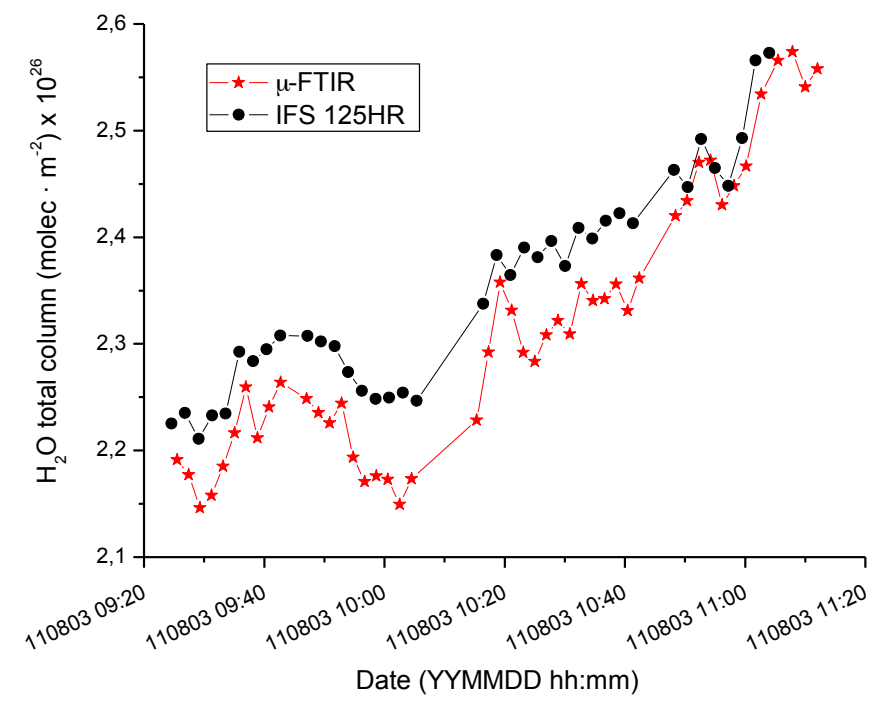

FIGURE 3. $\mathrm{H}_{2} \mathrm{O}$ total column amounts for the $\mu$-FTIR and the IFS $125 \mathrm{HR}$ in 2 hour of measurements and for measurements that coincide within 10 minutes (08 August 2012 from 09:20 UTC to 11:20 UTC). The $\mu$-FTIR data are scaled according to the scaling factor obtained in Fig. 2 ( $\mathrm{SF}=0.693)$.

\section{CONCLUSION}

A very compact $(14.6 \times 10.5 \times 7 \mathrm{~cm})$, commercial and very low resolution $(\sim 18 \mathrm{~cm}-1)$ Fourier transform spectrometer ( $\mu$-FTIR) for the remote sensing of total column amounts of $\mathrm{H}_{2} \mathrm{O}$ has been presented. The instrument is lightweight $(<1 \mathrm{~kg})$, and therefore very portable. Very low resolution spectra with a good signal-to-noise level can be acquired within every 2 minutes allowing for a high measurement frequency.

An inter-comparison with respect to collocated high resolution measurements performed at the Izaña observatory with a Bruker IFS $125 \mathrm{HR}$ during a year documents the repeatability of the $\mu$-FTIR data (precision better than $4 \%$ ), but also indicates a large wet bias. The reason for this wet bias is currently being investigated; possibilities include very low resolution spectra and spectroscopy for the spectral region studied. 


\section{ACKNOWLEDGMENTS}

E. Sepúlveda enjoys a pre-doctoral fellowship from the Spanish Ministry of Education. M. Schneider is supported by the European Research Council under the European Community's Seventh Framework Programme (FP7/20072013)/ERC Grant agreement number 256961. The research leading to these results has received funding from the European Community's Seventh Framework Programme (FP7/2007-2013) within the NORS project (grant agreement no. 284421). We are grateful to NASA Goddard Space Flight Center for providing the temperature and pressure profiles of the National Centers for Environmental Prediction via the automailer system.

\section{REFERENCES}

1. J. Strong and G. A. Vanasse, J. Opt. Soc. Am. 50, 113-118 (1960).

2. F. Hase, Atmos. Meas. Tech. 5, 603-610, doi:10.5194/amt-5-603-2012 (2012).

3. F. Hase, J. W. Hannigan, M. T. Coffey, A. Goldman, M. Höpfner, N. B. Jones, C. P. Rinsland and S. W. Wood, J. Quant. Spectrosc. Ra. 87, 25-52, 2004

4. M. Schneider, E. Sepúlveda, O. García, F. Hase and T. Blumenstock, Atmos. Meas. Tech. 3, 1785-1795, doi:10.5194/amt-3-17852010 (2010). 